\title{
Exogenous $\alpha$-calcitonin gene-related peptide attenuates lipopolysaccharide-induced acute lung injury in rats
}

\author{
WANG YANG ${ }^{1,2}$, MENG XV $^{1,2}$, WAN CHAO YANG ${ }^{1,2}$, NAN WANG $^{1,2}$, XUE ZHONG ZHANG ${ }^{1,2}$ and WEN ZHI LI $I^{1,2}$ \\ ${ }^{1}$ Department of Anesthesiology, The Second Affiliated Hospital of Harbin Medical University; ${ }^{2}$ Anesthesiology Key Laboratory, \\ Harbin Medical University, Education Department of Heilongjiang Province, Harbin, Heilongjiang 150001, P.R. China
}

Received February 14, 2014; Accepted October 24, 2014

DOI: $10.3892 / \mathrm{mmr} .2015 .3620$

\begin{abstract}
Calcitonin gene-related peptide ( $\alpha$-CGRP) is a 37 amino-acid neuropeptide that is primarily released from C-type sensory neurons. $\alpha$-CGRP exerts multiple modulatory effects on immune responses and visceral organ function, but the role of exogenous $\alpha$-CGRP in lipopolysaccharide (LPS)-induced acute lung injury (ALI) has remained to be elucidated. Forty-eight rats were randomized to receive continuous intraperitoneal infusion of $\alpha$-CGRP $(0.4 \mu \mathrm{g} / \mathrm{kg} / \mathrm{min})$ or normal saline for $30 \mathrm{~min}$, followed by intratracheal injection of $0.5 \mathrm{mg} / \mathrm{kg}$ LPS or saline. There were four groups of animals: The saline-saline (S-S) group; the saline- $\alpha$-CGRP (S-C) group; the LPS-saline (L-S) group and the LPS- $\alpha$-CGRP (L-C) group. Mean arterial pressure and arterial blood gases were assessed prior to $\alpha$-CGRP and LPS administration and every hour following LPS treatment. After $4 \mathrm{~h}$, bronchoalveolar lavage was performed and used to assess total cell count and levels of tumor necrosis factor- $\alpha$, interleukin-1 $\beta$, intracellular cell adhesion molecule 1 and macrophage inflammatory protein 2 . Lung tissue was also collected for assessing wet-to-dry (W/D) ratio, histology and Evans blue (EB) dye extravasation. Pulmonary $\alpha$-CGRP concentration and $\alpha$-CGRP receptor expression were also examined, and inducible cyclic adenosine monophosphate early repressor (ICER) and TNF- $\alpha$ mRNA expression levels were measured. Treatment with exogenous $\alpha$-CGRP improved oxygenation during LPS-induced ALI. Correspondingly, histological injury, total cell count, inflammatory cytokine levels, W/D ratio and EB dye extravasation were also significantly reduced. $\alpha$-CGRP receptor 1 expression was noted in pulmonary endothelial cells and alveolar macrophages and $\alpha$-CGRP receptor expression levels were decreased during ALI, whereas pulmonary $\alpha$-CGRP expression was continu-
\end{abstract}

Correspondence to: Professor Wen Zhi Li, Department of Anesthesiology, The Second Affiliated Hospital of Harbin Medical University, 148 Baojian Street, Harbin, Heilongjiang 150001, P.R. China

E-mail:wenzhili9@126.com

Key words: acute lung injury, calcitonin gene-related peptide, lipopolysaccharide ously increased. Furthermore, exogenous $\alpha$-CGRP induced upregulation of ICER during LPS-induced ALI. In conclusion, exogenous $\alpha$-CGRP improved oxygenation and ameliorated lung damage in LPS-induced ALI, and these effects were associated with the upregulation of ICER.

\section{Introduction}

Acute lung injury (ALI) and its more severe form, acute respiratory distress syndrome (ARDS), are critical illnesses with high rates of mortality (1). The pathological hallmarks of these conditions are diffuse alveolo-capillary injury and pulmonary hyperpermeability, associated with a dysregulated inflammatory response $(2,3)$. These abnormalities are associated with the clinical manifestations of acute onset and progressive deterioration of respiratory function (4).

Over the past decades, modulation of the inflammatory response and visceral organ function by the autonomic nervous system have been extensively investigated. In the lungs, rich supplies of C-type sensory nerves, which are vagal afferent nerves, innervate the alveolar walls, ducts and pulmonary capillaries (5). Exposure to exogenous irritants or endogenous inflammatory stimuli triggers $\mathrm{C}$-type nerve endings to release neuropeptides, including $\alpha$-calcitonin gene-related peptide $(\alpha$-CGRP). In addition to being released from nerve endings, $\alpha$-CGRP is synthesized and secreted by epithelial cells and macrophages under inflammatory stress conditions in vitro $(6,7)$.

$\alpha$-CGRP is a 37 amino-acid peptide that functions via the $\alpha$-CGRP receptor, which comprises calcitonin receptor-like receptor (CRLR) and receptor activity-modifying protein 1 (RAMP1) (8). Initially, $\alpha$-CGRP was demonstrated to potentiate inflammation via its vasodilatory properties (9). $\alpha$-CGRP later emerged as an anti-inflammatory agent, which was found to act via its ability to upregulate interleukin (IL)-10 and IL-10-independent inducible cyclic adenosine monophosphate early repressor (ICER), as well as inhibit nuclear factor kappa B activity in vitro (10-12). Recent studies have indicated that $\alpha$-CGRP mediates protective effects in animal models of allergic airway inflammation, hyperoxic lung injury, lung ischemia/reperfusion injury and lung fibrosis (13-16). In addition, studies have demonstrated that $\alpha$-CGRP prevented lipopolysaccharide (LPS)-induced lethal endotoxemia and acute liver injury in mice $(17,18)$. LPS, a Gram-negative bacterial 
endotoxin, is a causative agent that initiates ALI/ARDS. Intratracheal LPS instillation has been widely accepted as an ALI/ARDS experimental model (19). Therefore, the present study aimed to investigate whether exogenous $\alpha$-CGRP had a protective role in LPS-induced ALI, and examined $\alpha$-CGRP and $\alpha$-CGRP receptor expression during LPS-induced ALI. Furthermore, the present study aimed to elucidate whether exogenous $\alpha$-CGRP effects were associated with ICER.

\section{Materials and methods}

Animals and experimental groups. The present study was approved by the ethics committee of the Harbin Medical University (Harbin, China). All procedures were performed according to the Harbin Medical University Institutional Animal Care and Use Committee guidelines and national guidelines for the treatment of animals. The adult male Sprague Dawley rats weighing 240-280 g used in the present study were obtained from Beijing Vital River Laboratory Animal Technology Co., Ltd. (Beijing, China). The rats were maintained under a controlled temperature $\left(24 \pm 2^{\circ} \mathrm{C}\right)$ on a $12 \mathrm{~h}$ light/12 $\mathrm{h}$ dark cycle, and were given ad libitum acces to standard laboratory chow and tap water. Rats were assigned to receive continuous intraperitoneal infusions of $\alpha$-CGRP or $0.9 \%$ normal saline. They subsequently underwent either LPS or $0.9 \%$ normal saline intratracheal instillation. Rats were divided into four groups: $i$ ) Saline-saline (S-S) group, $\mathrm{n}=10$; ii) saline- $\alpha$-CGRP (S-C) group, $\mathrm{n}=10$; iii) LPS-saline $(\mathrm{L}-\mathrm{S})$ group, $\mathrm{n}=14$ and $i v$ ) LPS- $\alpha$-CGRP (L-C) group, $\mathrm{n}=14$. Four animals from each group were used for the evaluation of pulmonary permeability with Evans blue (EB) dye.

Experimental protocol. Rats were anesthetized by intraperitoneal injection of pentobarbital $(60 \mathrm{mg} / \mathrm{kg}$; Shanghai Xitang Biotechnology Co., Ltd., Shanghai, China). Subsequently, a tracheostomy was performed, the rats were mechanically ventilated [fraction of insprired oxygen $\left(\mathrm{FiO}_{2}\right), 0.6$; rate, 65 breaths/min; tidal volume, $8 \mathrm{ml} / \mathrm{kg}$ and positive end-expiratory pressure, $3 \mathrm{~cm} \mathrm{H}_{2} \mathrm{O}$; Harvard Inspira ASV, Harvard Apparatus, Holliston, MA, USA] and femoral arterial and vein cannulas were inserted. Anesthesia and muscle relaxation were maintained by intravenous pentobarbital $(30 \mathrm{mg} / \mathrm{kg} / \mathrm{h})$ and pancuronium bromide $(0.2 \mathrm{mg} / \mathrm{h}$; Gedeon Richter Ltd., Budapest, Hungary) injection. Warming pads were used to maintain the animals' body temperature at $36.5-37.5^{\circ} \mathrm{C}$. Electrocardiography (ECG), arterial pressure and rectal temperatures were continuously monitored (AcqKnowledge and MP150 version 2.7.2; BIOPAC Systems, Inc., Goleta, CA, USA), and femoral arterial blood was used for blood gas analysis. In the S-C and L-C groups, the animals were intraperitoneally pre-treated with $\alpha$-CGRP (C0292; Sigma-Aldrich, St. Louis, MO, USA) at $0.4 \mu \mathrm{g} / \mathrm{kg} / \mathrm{min}$ for $30 \mathrm{~min}$. This dose was determined with pilot experiments and did not result in a significant decrease in the mean arterial pressure (MAP), while the oxygenation index was significantly improved. In the S-S and L-S groups, an equal volume of normal saline was infused over $30 \mathrm{~min}$. Thereafter, in the L-S and L-C groups, $0.5 \mathrm{mg} / \mathrm{kg}$ LPS (Escherichia coli, O55:B5; Sigma-Aldrich) was administered intratracheally in $0.3 \mathrm{ml}$ normal saline. In the $\mathrm{S}-\mathrm{S}$ and $\mathrm{S}-\mathrm{C}$ groups, $0.3 \mathrm{ml}$ normal saline was administered. MAP, temperature, heart rate and arterial blood gases $\left(\mathrm{pH}, \mathrm{PaO}_{2}, \mathrm{PaCO}_{2}\right.$ ) were recorded hourly throughout the experiments. Following $4 \mathrm{~h}$, animals were sacrificed by exsanguination, and the heart-lung block was dissected from the thorax. Additionally, bronchoalveolar lavage fluid (BALF) was obtained from the left lung, the upper right lobe was harvested for the wet-dry (W/D) weight ratio and the middle right lobe was harvested for histology. All remaining lung tissue was frozen in liquid nitrogen and kept at $-80^{\circ} \mathrm{C}$ for further analyses.

$B A L F$ collection and total cell counts. The left lung was lavaged three times with $3 \mathrm{ml}$ cold normal saline through a tracheal cannula. BALF was centrifuged at $1,500 \mathrm{rpm}$ for $10 \mathrm{~min}$ at $4^{\circ} \mathrm{C}$. The supernatant was frozen at $-20^{\circ} \mathrm{C}$ for later analysis. The cells were resuspended in $1 \mathrm{ml} 0.9 \%$ normal saline, subjected to Wright-Giemsa staining (Nanjing Jiancheng Biotechnology Institute, Nanjing, China) and counted using a Neubauer chamber (Anxin Optical Instrument Manufacture Co., Ltd., Shanghai, China).

The upper right lobe was weighed immediately following excision, and the dry weight was determined after heating the lungs at $80^{\circ} \mathrm{C}$ for $48 \mathrm{~h}$. The W/D ratio was calculated by dividing the wet weight by the dry weight.

Pulmonary permeability. To assess pulmonary permeability, EB extravasation was measured as previously described (20). Animals received EB dye (30 mg/kg; Sigma-Aldrich) intravenously $2 \mathrm{~h}$ prior to sacrification ( $\mathrm{n}=4$ per group). The lungs were perfused free of blood with saline via a thoracotomy, excised en bloc, blotted dry and weighed. Pulmonary tissue was homogenized in saline $(0.1 \mathrm{ml} / 100 \mu \mathrm{g}$ tissue $)$ and incubated with two volumes of formamide (Merck Millipore, Billerica, MA, USA) for dye extraction $\left(24 \mathrm{~h}, 37^{\circ} \mathrm{C}\right)$. The supernatant was separated from the lung tissue by centrifugation at 5,000 x g for $30 \mathrm{~min}$, and the optical supernatant density was determined spectrophotometrically at $620 \mathrm{~nm}$. The extravasated EB concentration was calculated against a standard curve and expressed as micrograms of EB dye per gram of lung tissue.

Histology. The middle right lobe was fixed in $4 \%$ paraformaldehyde (Sigma-Aldrich) for $48 \mathrm{~h}$, embedded in paraffin and then cut into $5-\mu \mathrm{m}$ sections. The sections were stained with hematoxylin and eosin (H\&E; Sigma-Aldrich) and examined by light microscopy (Eclipse 80i; Nikon Corporation, Tokyo, Japan).

BALF cytokine/chemokine measurements. BALF tumor necrosis factor (TNF)- $\alpha$, IL-1 $\beta$, macrophage-inflammatory protein-2 (MIP2) and intracellular cell adhesion molecule 1 (ICAM-1) levels were measured using Rat TNF- $\alpha$ Boster ${ }^{\mathrm{TM}}$ ELISA kit, Rat IL-1 $\beta$ Boster ${ }^{\mathrm{TM}}$ ELISA kit, Rat MIP2 Boster ${ }^{\mathrm{TM}}$ ELISA kit and Rat ICAM-1 Boster ${ }^{\mathrm{TM}}$ ELISA kit, according to the manufacturer's instructions (Boster Systems, Inc., Wuhan, China).

$\alpha$-CGRP measurement in the lung parenchyma. $\alpha$-CGRP concentration in lung tissue from the S-S and L-S groups was analyzed at each time-point ( $n=4$ per point) with a commercial ELISA kit (CGRP kit; Uscn Life Science, Inc., Wuhan, China). 
Immunohistochemistry. Immunohistochemistry was performed on paraffin-embedded sections. Following deparaffinization and rehydration in two changes of xylene and six different concentrations of alcohol (Sigma-Aldrich), sections were retrieved in a retrieval solution $(9 \mathrm{mM}$ sodium citrate, $2 \mathrm{mM}$ citric acid) at $120^{\circ} \mathrm{C}$ for $3 \mathrm{~min}$ and blocked with $2 \%$ bovine serum albumin (Boster Systems, Inc.) in phosphate-buffered saline (PBS) for $30 \mathrm{~min}$ once cool. Sections were immunostained with purified polyclonal goat anti-rat CRLR (1:20 dilution; Santa Cruz Biotechnology, Inc., Dallas, TX, USA) overnight at $4^{\circ} \mathrm{C}$. Sections were incubated with a rabbit anti-rat secondary immunoglobulin $\mathrm{G}$ antibody (1:400; Boster Systems, Inc.) for $30 \mathrm{~min}$. Specific labeling was detected with 3,3'-diaminobenzidine substrate (Sigma-Aldrich). All sections were counterstained with hematoxylin. A sample treated analogously but with omission of the primary antibody served as a negative control.

Quantitative reverse-transcription polymerase chain reaction (RT-qPCR). Lung tissue total RNA was isolated using an RNA pure kit (BioTeke Corp., Beijing, China) according to the manufacturer's instructions; $1 \mu \mathrm{g}$ total RNA was used in a $20-\mu 1$ reaction to synthesize cDNA with a High-Capacity cDNA Reverse Transcription kit (Applied Biosystems, Life Technologies, Foster City, CA, USA). qRT-PCR was performed using an Accupower 2xGreenstar qPCR Master mix (Bioneer, Daejeon, Korea). Rat $\beta$-actin mRNA was used as the internal control. The primer sequences used were as follows ( $\left.5^{\prime}-3^{\prime}\right)$ : $\beta$-actin forward, GTC AGG TCA TCA CTA TCG GCA AT and reverse, AGA GGT CTT TAC GGA TGT CAA CGT; CRLR forward, CAA ACA GAC TTG GGA GTC ACT AG and reverse, CTG CAA CGT CAT TCC AGC AT; RAMP1 forward, CAC CAA ACT CGT GGC AAA C and reverse, GGG GGA GCA CAA TGA AAG G; ICER forward, GCT CCT ACT ACT GCT TTG $C$ and reverse, GCT TTC GAG TTG TTG CTT CTT C; TNF- $\alpha$ forward, CTT CTC ATT CCT GCT CGT GG and reverse, TCC TCC GCT TGG TGG TTT. All primers were designed and synthesized by Settlebio, Co. (Harbin, China). The reaction was performed as follows: Denaturation at $94^{\circ} \mathrm{C}$ for $2 \mathrm{~min}, 30 \mathrm{cycles}$ at $94^{\circ} \mathrm{C}$ for $30 \mathrm{sec}, 55^{\circ} \mathrm{C}$ for $60 \mathrm{sec}$ and $72^{\circ} \mathrm{C}$ for $50 \mathrm{sec}$, followed by $10 \mathrm{~min}$ at $75^{\circ} \mathrm{C}$. Each sample was evaluated in duplicate. The amplification specificity of PCR products was confirmed by melting curve analysis, agarose gel electrophoresis and sequencing. Relative messenger RNA (mRNA) levels were calculated using the $2^{-\Delta(\Delta C T)}$ method and normalized to levels of $\beta$-actin as a reference (21).

Western blot analyses. Total protein was obtained from lung tissue homogenates in a membrane lysis buffer containing a detergent [16 mM 3-[(3-cholamidopropyl) dimethylammonio]-1-propanesulfonate, $20 \mathrm{mM}$ Tris- $\mathrm{HCl}$, $\mathrm{pH} 7.5,1 \mathrm{mM} \mathrm{Na}{ }_{2}$ EDTA and $1 \mathrm{mM}$ dithiothreitol] (Sigma-Aldrich) with protease inhibitors (1 $\mathrm{mM}$ benzamidine, $1 \mu \mathrm{g} / \mathrm{ml}$ leupeptin, $10 \mu \mathrm{g} / \mathrm{ml}$ soybean trypsin inhibitor and 0.5 mM PMSF; Sigma-Aldrich), as previously described (22). Protein concentrations were determined using a Bradford reagent assay (23). CRLR and RAMP1 western blot analysis was performed using $30 \mu \mathrm{g}$ protein. Proteins were separated by $10-15 \%$ SDS-PAGE and transferred to polyvinylidene difluoride membranes (EMD Millipore, Billerica, MA, USA).

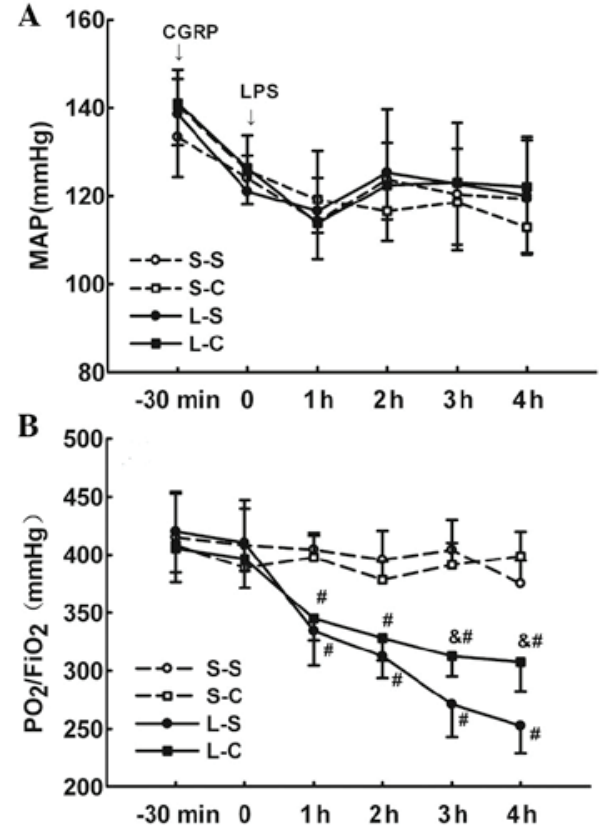

Figure 1. (A) MAP and (B) $\mathrm{PaO}_{2} / \mathrm{FiO}_{2}$ was determined prior to $\alpha$-CGRP and LPS treatment and every hour following LPS treatment in the four groups. S-S and S-C groups: Intraperitoneal infusion of saline or $\alpha$-CGRP, followed by intratracheal instillation of saline. L-S and L-C groups: Intraperitoneal infusion of saline or $\alpha$-CGRP, followed by intratracheal instillation of LPS. Values are expressed as the mean \pm standard error of the mean $(n=6$ for $\mathrm{S}-\mathrm{S}$ and $\mathrm{S}-\mathrm{C}$ groups, $\mathrm{n}=10$ for $\mathrm{L}-\mathrm{S}$ and $\mathrm{L}-\mathrm{C}$ groups). ${ }^{\#} \mathrm{P}<0.05$ vs. $\mathrm{S}-\mathrm{S}$ group; ${ }^{\&} \mathrm{P}<0.05$ vs. L-S group. Repeated measures tests followed by Tukey's test were performed. MAP, mean arterial blood pressure; $\alpha$-CGRP, $\alpha$-calcitonin gene-related peptide; LPS, lipopolysaccharide; S-S, saline-saline group; S-C, saline- $\alpha$-CGRP group; L-S, LPS-saline group; L-C, LPS- $\alpha$-CGRP group; $\mathrm{PaO}_{2} / \mathrm{FiO}_{2}$, ratio of oxygen tension to inspired oxygen fraction.

The membranes were blocked for $2 \mathrm{~h}$ in Tris-buffered saline containing $0.1 \%$ Tween and 5\% non-fat dried milk (Nanjing Jiancheng Biotechnology Institute) and incubated with primary antibody at $4^{\circ} \mathrm{C}$ overnight. The primary antibodies used in this experiment were goat polyclonal anti-CRLR (sc-18007; Santa Cruz Biotechnology, Inc.) at a 1:200 dilution, rabbit polyclonal anti-RAMP1 (sc-11379; Santa Cruz Biotechnology, Inc.) at a 1:300 dilution and mouse polyclonal anti- $\beta$-actin (Boster) at a 1:1,000 dilution. Following washing, the membranes were incubated with horseradish peroxidase-conjugated enhanced chemiluminescence (ECL) rabbit anti-goat, goat anti-rabbit or rabbit anti-mouse secondary antibodies. The ECL western blotting system (Beyotime Institute of Biotechnology, Haimen, China) was used for detection. Proteins were quantified with a digitized image and normalized against $\beta$-actin.

Statistical analysis. Values are expressed as the mean \pm standard error of the mean. MAP, $\mathrm{PaO}_{2} / \mathrm{FiO}_{2}$ and $\alpha$-CGRP analyses between groups were assessed by repeated measures tests followed by Tukey's test. Differences in other data were examined using one-way analysis of variance followed by least significant difference test or unpaired Student's t-test. All statistical assessments were two-sided and $\mathrm{P}<0.05$ was considered to indicate a statistically significant difference between values. Statistical analyses were carried out using either SAS 9.2 (SAS Institute Inc., Cary, NC, USA) or SPSS 21.0 (IBM, Armonk, NY, USA). 
A.

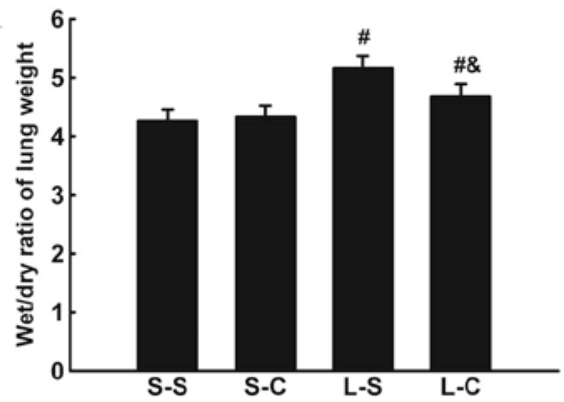

B

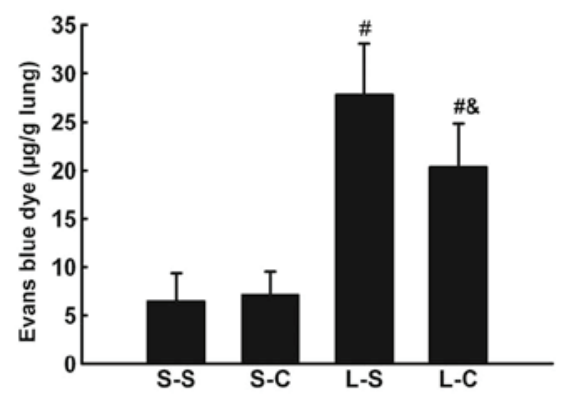

C

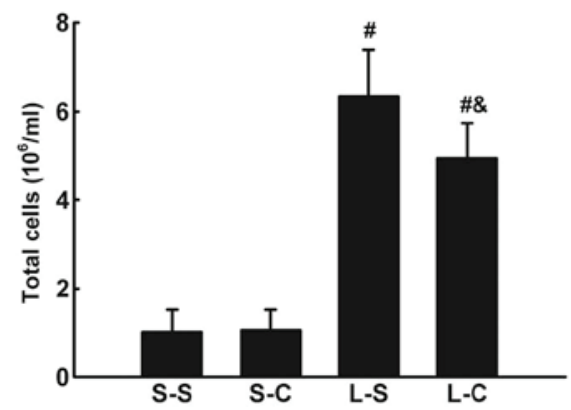

Figure 2. (A) Wet/dry ratio of lung weight. (B) Evans blue dye extravarsation in lung homogenate. (C) Total cell count in bronchoalveolar lavage fluid following $4 \mathrm{~h}$ in the S-S, S-C, L-S and L-C groups. Values are expressed as the mean \pm standard error of the mean $(n=4-10) .{ }^{~} \mathrm{P}<0.05$ vs. $\mathrm{S}-\mathrm{S}$ group; ${ }^{\&} \mathrm{P}<0.05$ vs. L-S group. One-way analysis of variance followed by the least significant difference test were used. S-S, saline-saline group; S-C, saline- $\alpha$-CGRP group; L-S, LPS-saline group; L-C, LPS- $\alpha$-CGRP group; $\alpha$-CGRP, $\alpha$-calcitonin gene-related peptide.

\section{Results}

a-CGRP rescues $\mathrm{PaO}_{2} / \mathrm{FiO}_{2}$ decrease following LPS instillation The MAP was decreased in the four groups during the course of the experiment. There were no significant differences in MAP between the four groups at any time-point ( $\mathrm{P}>0.05$; Fig. 1A).

Instillation of LPS resulted in a significant decrease in $\mathrm{PaO}_{2} / \mathrm{FiO}_{2}$ in the L-S and L-C groups compared to that of the $\mathrm{S}-\mathrm{S}$ and $\mathrm{S}-\mathrm{C}$ groups following $1 \mathrm{~h}$ of injury $(\mathrm{P}<0.05$ at each time-point). Animals in the L-C group had significantly higher $\mathrm{PaO}_{2} / \mathrm{FiO}_{2}$ levels at 3 and $4 \mathrm{~h}$ after LPS instillation compared with those in the L-S group $(312.50 \pm 17.27$ vs. $270.90 \pm 27.80 \mathrm{mmHg}, \mathrm{P}<0.05$ at $3 \mathrm{~h} ; 307.4 \pm 25.05$ vs. $252.6 \pm 23.88 \mathrm{mmHg}, \mathrm{P}<0.05$ at $4 \mathrm{~h}$ ). There were no significant differences between the two S-S and S-C groups (Fig. 1B).

$\alpha-C G R P$ rescues $L P S$-induced $W / D$ weight ratio increase and $E B$ dye accumulation. The lung W/D weight ratio was significantly increased $4 \mathrm{~h}$ following LPS instillation $(\mathrm{P}<0.05$
A

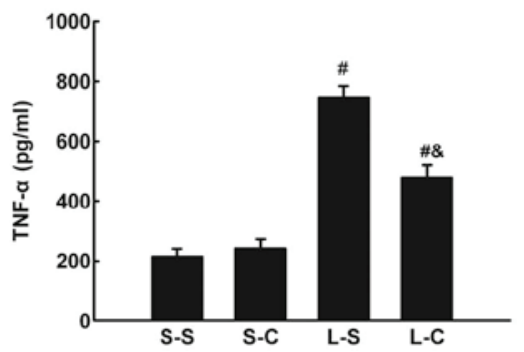

B

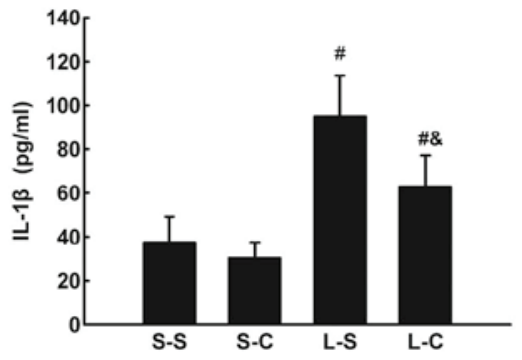

C

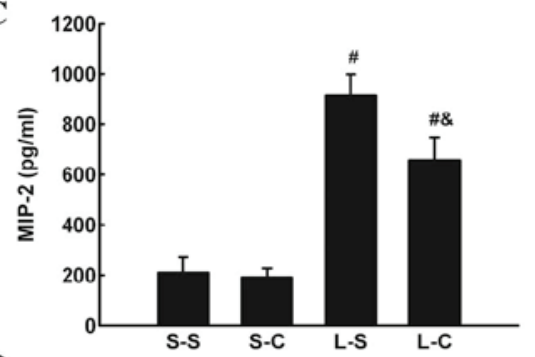

D

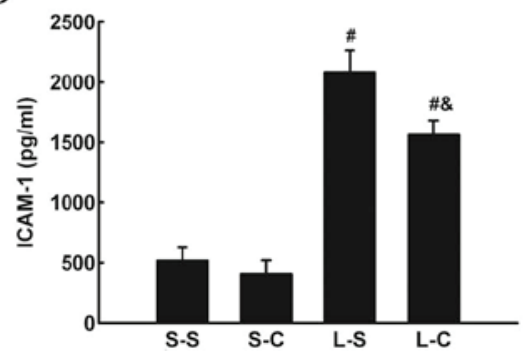

Figure 3. (A) TNF- $\alpha$, (B) IL-1 $\beta$, (C) MIP-2 and (D) ICAM-1 in bronchoalveolar lavage fluid following $4 \mathrm{~h}$ in the S-S, S-C, L-S and L-C groups. Values are expressed as the mean \pm standard error of the mean $(\mathrm{n}=6$ for $\mathrm{S}-\mathrm{S}$ and $\mathrm{S}-\mathrm{C}$ groups, $\mathrm{n}=10$ for $\mathrm{L}-\mathrm{S}$ and $\mathrm{L}-\mathrm{C}$ groups). ${ }^{*} \mathrm{P}<0.05$ vs. $\mathrm{S}-\mathrm{S}$ group; ${ }^{\circledR} \mathrm{P}<0.05$ vs. L-S group. One-way analysis of variance followed by least significant difference test were used. TNF- $\alpha$, tumor necrosis factor-alpha; IL-1 $\beta$, interleukin-1 beta; MIP-2, macrophage inflammatory protein-2; ICAM-1, intercellular adhesion molecule-1; S-S, saline-saline group; S-C, saline- $\alpha$-CGRP group; L-S, LPS-saline group; L-C, LPS- $\alpha$-CGRP group; $\alpha$-CGRP, $\alpha$-calcitonin gene-related peptide.

vs. S-S group) (Fig. 2A), $\alpha$-CGRP infusion significantly attenuated the lung W/D weight ratio increase $(4.674 \pm 0.22$ vs. $5.16 \pm 0.21, \mathrm{P}<0.05)$.

LPS induced an increase in EB dye accumulation in lung parenchyma $(\mathrm{P}<0.05$ vs. S-S group; Fig. $2 \mathrm{~B}) . \alpha$-CGRP treatments resulted in a significant decrease in EB dye accumulation $(20.35 \pm 4.51$ vs. $27.8 \pm 5.29 \mu \mathrm{g} / \mathrm{g}$ lung, $\mathrm{P}<0.05)$.

a-CGRP attenuates the LPS-induced pulmonary inflammatory response. Total BALF cell numbers were significantly increased $4 \mathrm{~h}$ following LPS instillation $(\mathrm{P}<0.05$ vs. S-S group; Fig. 2C) and L-C group cell numbers were significantly lower than those of the L-S group $\left(4.94 \pm 0.78 \times 10^{6} \mathrm{vs}\right.$. $\left.6.34 \pm 1.06 \times 10^{6}, \mathrm{P}<0.05\right)$. 

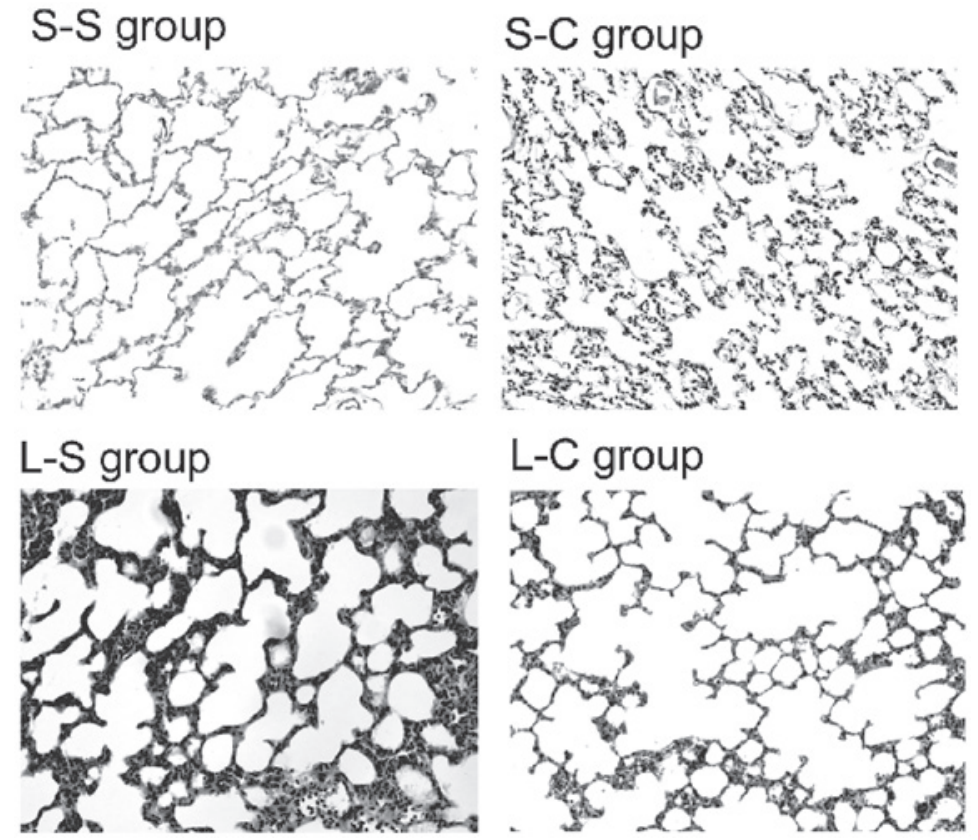

Figure 4. Images of representative lung sections in the S-S, S-C, L-S and L-C groups. Hematoxylin and eosin staining, magnification $x 400$. Lung sections were taken from rats $4 \mathrm{~h}$ following treatment. S-S, saline-saline group; S-C, saline- $\alpha$-CGRP group; L-S, LPS-saline group; L-C, LPS- $\alpha$-CGRP group; $\alpha$-CGRP, $\alpha$-calcitonin gene-related peptide.

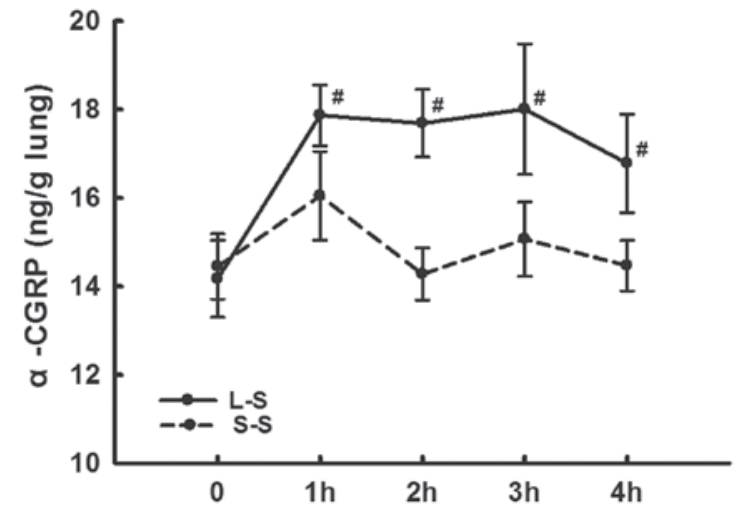

Figure 5. Levels of $\alpha$-CGRP in the lung homogenate at each time-point in the $\mathrm{L}-\mathrm{S}$ and $\mathrm{S}-\mathrm{S}$ groups. Values are expressed as the mean \pm standard error of the mean ( $\mathrm{n}=4$ for each group). ${ }^{*} \mathrm{P}<0.05$ vs. $\mathrm{S}-\mathrm{S}$ group. Repeated measures tests followed by Tukey's test were performed. $\alpha$-CGRP, $\alpha$-calcitonin gene-related peptide; S-S, saline-saline group; L-S, LPS-saline group.

The TNF- $\alpha$, IL-1 $\beta$, IL-6, MIP-2, and ICAM-1 protein levels in BALF were significantly increased in the L-S and $\mathrm{L}-\mathrm{C}$ groups compared with those of the $\mathrm{S}-\mathrm{S}$ and $\mathrm{S}-\mathrm{C}$ groups. The L-C group had significantly lower TNF- $\alpha$, IL-1 $\beta$, MIP-2, and ICAM-1 levels in BALF compared with those of the L-S group $(\mathrm{P}<0.05$; Fig. 3A-D).

$\alpha$-CGRP abrogates LPS-induced lung injury. Histological analysis demonstrated that lungs in the S-S and S-C groups exhibited no morphological injuries (Fig. 4). A representative lung tissue section from the L-S group demonstrated increased wall thickness and marked inflammatory cell infiltration compared with that of the S-S group. Furthermore, $\alpha$-CGRP pre-treatment decreased wall thickness and inflammatory cell infiltration.
LPS instillation increases $\alpha$-CGRP expression levels and decreases $\alpha$-CGRP receptor expression levels. The lung homogenate $\alpha$-CGRP levels in the L-S group were significantly higher than those in the S-S group from $1 \mathrm{~h}$ following LPS administration at each time-point $(\mathrm{P}<0.05$; Fig 5$)$.

Immunohistochemistry detected CRLR expression in pulmonary microvascular endothelial cells and alveolar macrophages in LPS-induced lung injury (Fig. 6Aa and Ab). RT-qPCR and western blot analysis revealed lower mRNA and protein expression levels of CRLR and RAMP1 in the L-S group compared with those in the $\mathrm{S}-\mathrm{S}$ group $(\mathrm{P}<0.05$; Fig. 6B and C; Fig. 7).

$\alpha-C G R P$ increases ICER mRNA expression and decreases $T N F-\alpha$ mRNA expression following LPS instillation. RT-qPCR assays demonstrated that ICER mRNA expression levels were significantly higher in the L-C group at two and $4 \mathrm{~h}$ than those in the L-S group $(\mathrm{P}<0.05$; Fig. 8A). TNF- $\alpha$ mRNA expression was significantly lower in the L-C group compared with those in the L-S group at two and $4 \mathrm{~h}(\mathrm{P}<0.05$; Fig. 8B).

\section{Discussion}

In the present study, it was demonstrated that intratracheal instillation of LPS induced ALI. $\alpha$-CGRP infusion attenuated LPS-induced ALI as indicated by improved oxygenation, ameliorated histological changes, reduced EB leakage as well as decreased W/D ratio, total cell count and cytokine levels in BALF. The role of exogenous $\alpha$-CGRP in LPS-induced ALI was associated with upregulation of the transcription factor ICER, which inhibits the transcription of TNF- $\alpha$.

$\alpha$-CGRP is a vasodilatory neuropeptide that exerts broad regulatory effects in physiological and pathophysiological situations. Studies have demonstrated beneficial effects of 
A a

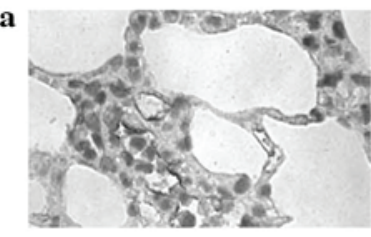

b

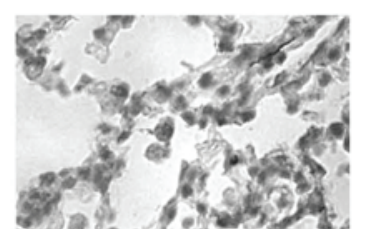

B

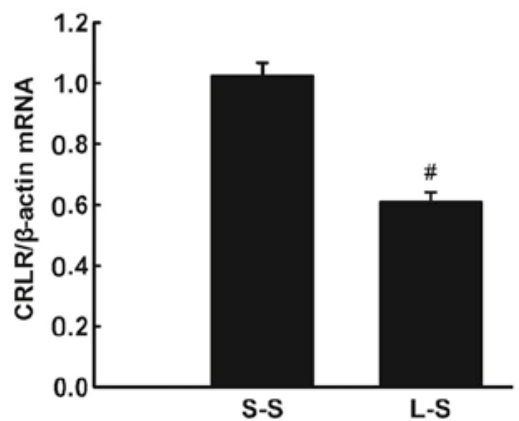

C

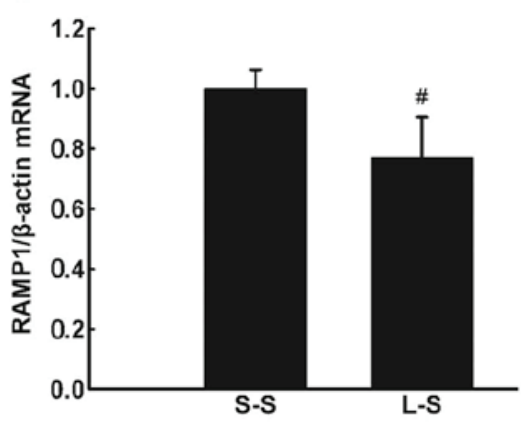

Figure 6. (A) Representative immunohistochemical images showing CRLR-positive cells in the lung of the L-S group. (a and b) CRLR-positive endothelial cells and alveolar macrophage cells (original magnification, x1,000). (B) CRLR and (C) RAMP1 were quantified by RT-qPCR in lung tissue $4 \mathrm{~h}$ following treatment in the S-S and L-S groups. For RT-qPCR analysis, $\beta$-actin mRNA was used as an internal control. X-fold induction was calculated referring to the

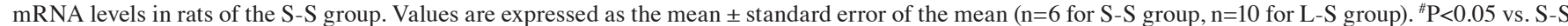
group. Significant differences between the two groups were evaluated using unpaired Student's t-test. S-S, saline-saline group; L-S, LPS-saline group; CRLR, calcitonin receptor-like receptor; RAMP1, receptor activity-modifying protein 1; RT-qPCR, quantitative reverse transcription polymerase chain reaction; mRNA, messenger RNA.

A

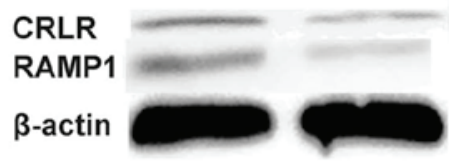

CRLR $\beta$-actin

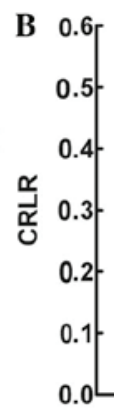

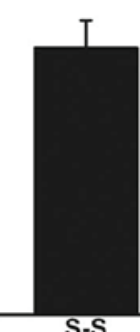

S-S

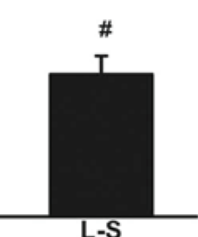

L-S

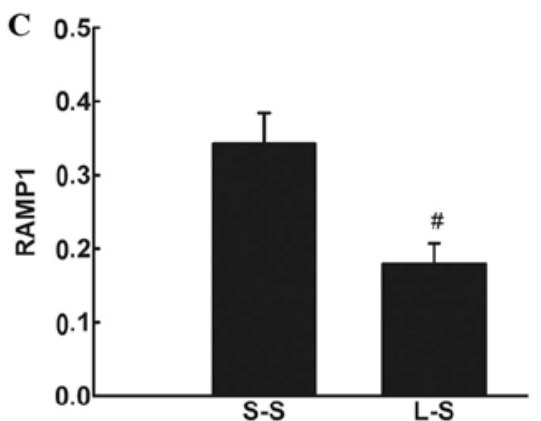

S-S

L-S

Figure 7. Western blot analysis of CRLR and RAMP1, quantified to $\beta$-actin levels in the S-S and L-S groups. Values are expressed as the mean \pm standard error of the mean (S-S group, $n=6 ; \mathrm{L}-\mathrm{S}$ group, $\mathrm{n}=10) .{ }^{\#} \mathrm{P}<0.05$ vs. $\mathrm{S}-\mathrm{S}$ group. Significant differences between the two groups were evaluated using unpaired Student's t-test. S-S, saline-saline group; L-S, LPS-saline group; CRLR, calcitonin receptor-like receptor; RAMP1, receptor activity-modifying protein 1.

A

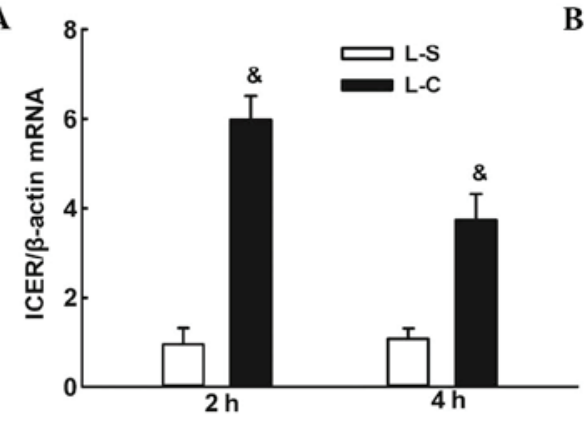

B

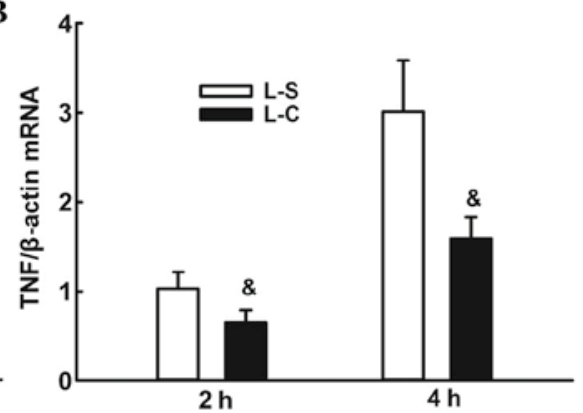

Figure 8. (A) Expression of ICER mRNA and (B) TNF- $\alpha$ mRNA was determined at two and $4 \mathrm{~h}$ by quantitative reverse transcription polymerase chain reaction in the L-S and L-C groups. $\beta$-actin was used as an internal control. X-fold induction was calculated referring to mRNA levels in rats of L-S group. Values are expressed as the mean \pm standard error of the mean $(n=6)$. ${ }^{\&} \mathrm{P}<0.05$ vs. $\mathrm{L}-\mathrm{S}$ group. Significant differences between the two groups were evaluated using unpaired Student's t-test. L-S, LPS-saline group; L-C, LPS-CGRP group; mRNA, messenger RNA; ICER, inducible cyclic adenosine monophosphate; TNF- $\alpha$, tumor necrosis factor-alpha.

$\alpha$-CGRP in cardiovascular diseases (22). In the respiratory system, $\alpha$-CGRP mediates protective effects in allergic airway inflammation, hyperoxic lung injury, lung ischemia/reperfusion injury and lung fibrosis (13-16). These observations are consistent with the results of the present study, in which exogenous $\alpha$-CGRP attenuated LPS-induced ALI.
In the present study, an increasing amount of $\alpha$-CGRP was detected in lung homogenates from $1 \mathrm{~h}$ following LPS instillation. $\alpha$-CGRP receptor expression by endothelial cells and alveolar macrophages provided the basis for the protective effects of $\alpha$-CGRP supplementation. The increasing amount of $\alpha$-CGRP observed is additionally supported by a previous 
study, in which intravenously administered LPS resulted in increased $\alpha$-CGRP in lungs (24).

The effects of $\alpha$-CGRP on blood pressure were evaluated. A previous study demonstrated that systemic administration of $\alpha$-CGRP $(0.38-38 \mu \mathrm{g} / \mathrm{kg})$ decreased MAP in a dose-dependent manner for $30 \mathrm{~min}$ in conscious rats (25). According to this observation and the pilot study preceding the present study, it was demonstrated that infusion of $0.4 \mu \mathrm{g} / \mathrm{kg} / \mathrm{min} \alpha$-CGRP for $30 \mathrm{~min}$ did not significantly decrease MAP during LPS-induced ALI. Furthermore, oxygenation capability, expressed as $\mathrm{PaO}_{2} / \mathrm{FiO}_{2}$, was significantly improved with exogenous $\alpha$-CGRP administration in LPS-induced ALI. It was hypothesized that this effect was due to an attenuation of lung damage following LPS endotoxemia. Although there was no significant MAP decrease following $\alpha$-CGRP infusion, the possibility of deteriorated $\mathrm{PaO}_{2} / \mathrm{FiO}_{2}$ due to hypoxic pulmonary vasoconstriction inhibition cannot be excluded. Further studies are required in order to clarify the hemodynamic effects of $\alpha$-CGRP on LPS-induced ALI.

The inflammatory protein influx and capillary leakage were evaluated using the extravascular EB dye assay and W/D ratio. Lung hyperpermeability has been suggested to be a major characteristic of ALI (26). $\alpha$-CGRP pretreatment was demonstrated to significantly decrease protein influx and capillary leakage. Lung hyperpermeability reduction protects against LPS-induced ALI (27). It was hypothesized that this effect of $\alpha$-CGRP may be associated with endothelial barrier function stabilization, and potentially with adrenomedullin and intermedin, which are members of the calcitonin/ $\alpha$-CGRP peptide family (28-30).

Various inflammatory mediators, including the cytokines TNF- $\alpha$ and IL-1 $\beta$, the chemokine MIP2, and ICAM- 1 , have been demonstrated to cause lung damage in LPS-induced ALI (31-33). $\alpha$-CGRP administration attenuated the production of these inflammatory mediators during ALI. These results are supported by other studies that have demonstrated various anti-inflammatory effects of $\alpha$-CGRP in in vivo and in vitro models. In a murine endotoxemia model, $\alpha$-CGRP markedly attenuated serum TNF- $\alpha$ levels (17). MIP-2, which possesses neutrophil chemotactic activity, is mainly released from macrophages (34). Ma et al (7) demonstrated that exogenous $\alpha$-CGRP was able to stimulate, inhibit or have no effect on inflammatory mediator release in RAW macrophages in a dose-dependent manner. The results of the present study suggested that $0.4 \mu \mathrm{g} / \mathrm{kg} / \mathrm{min} \alpha$-CGRP may inhibit macrophage inflammatory activity in LPS-induced ALI. ICAM-1 mediates adhesion between pulmonary endothelial cells and neutrophils (35). Therefore, a decrease in ICAM-1 expression by exogenous $\alpha$-CGRP may indicate protective effects on the pulmonary endothelium. This hypothesis is similar to the results of a study by Huang et al (36), which demonstrated that $\alpha$-CGRP inhibited LPS-induced chemokine production in human dermal microvascular endothelial cells. Consistent with lower MIP-2 and ICAM-1 expression levels, a reduction in the number of inflammatory cells in BALF was also observed.

Immunohistochemical analysis also demonstrated that CRLR was mainly expressed by pulmonary endothelial cells and alveolar macrophages, which was consistent with the results of a previous human study (37). Expression of CRLR and RAMP1 was significantly reduced in LPS-induced ALI. The downregulation of CRLR and RAMP1 may indicate reduced efficacy of endogenous $\alpha$-CGRP signalling in LPS-induced lung injury, and administration of exogenous $\alpha$-CGRP potentially amplifies endogenous $\alpha$-CGRP effects in LPS-induced ALI. $\alpha$-CGRP receptor activation increases cellular cAMP levels, leading to the activation of protein kinse A (PKA) (38). PKA subunits are able to activate transcription factor cyclic adenosine monophosphate response element-binding protein, which may promote the transcription of ICER $(11,39)$. It has been shown that $\alpha$-CGRP inhibits the functions of various immune cells and dampens inflammation by ICER, which directly represses TNF- $\alpha$ transcription through inhibiting the TNF- $\alpha$ promoter $(11,40)$. Therefore, the expression of ICER and TNF- $\alpha$ was evaluated. ICER expression was upregulated and TNF- $\alpha$ mRNA expression levels were downregulated by $\alpha$-CGRP during ALI. Therefore, it was hypothesized that $\alpha$-CGRP attenuated ALI partially via ICER induction.

Aoki-Nagase et al (41) observed that endogenous $\alpha$-CGRP expression partially mediated acid-induced ALI in a 2-h mouse model that differed from the model used in the present study. It was suggested that this result was observed because $\mathrm{HCl}$ instillation can directly stimulate the $\mathrm{C}$ sensory nerve and cause a large, simultaneous release of $\alpha$-CGRP and substance P (42). A biphasic injury (with 1- and 4-h peaks in acid-induced ALI) also indicated that the initial injury may be caused by neurogenic inflammation (43). In LPS-induced ALI, however, LPS does not directly stimulate the $\mathrm{C}$ sensory nerve. Instead, LPS binds to Toll-like receptor 4 on parenchyma pulmonary cells to induce inflammation and lung damage, which stimulates C-type sensory neurons to release $\alpha$-CGRP (44). The enhanced $\alpha$-CGRP release under inflammatory stress exerts a negative feedback function by inhibiting local immunoreactions (45).

There were several limitations of the present study. $\alpha$-CGRP effects were only evaluated up to $4 \mathrm{~h}$ following LPS administration; however, injury usually peaks at $24-48 \mathrm{~h}$ post LPS administration. The pulmonary hemodynamic effects of $\alpha$-CGRP in LPS-induced ALI have also remained elusive. Furthermore, only the involvement of ICER was evaluated; whether other mechanisms are responsible for the protective effects of $\alpha$-CGRP remains to be elucidated.

In conclusion, the present study indicated that exogenous $\alpha$-CGRP infusion improved oxygenation and reduced lung damage during LPS-induced ALI. The protective effects of $\alpha$-CGRP observed were associated with ICER upregulation.

\section{Acknowledgements}

The present study was supported by the Major Basic Research Project of the Second Affiliated Hospital of Harbin Medical University (Harbin, China; no. 100286).

\section{References}

1. Zambon M and Vincent JL: Mortality rates for patients with acute lung injury/ARDS have decreased over time. Chest 133: $1120-1127,2008$.

2. Bachofen M and Weibel ER: Structural alterations of lung parenchyma in the adult respiratory distress syndrome. Clin Chest Med 3: 35-56, 1982.

3. Ware LB and Matthay MA: The acute respiratory distress syndrome. N Engl J Med 342: 1334-1349, 2000. 
4. Ware LB: Pathophysiology of acute lung injury and the acute respiratory distress syndrome. Semin Respir Crit Care Med 27: 337-349, 2006.

5. Coleridge JC and Coleridge HM: Afferent vagal C fibre innervation of the lungs and airways and its functional significance. Rev Physiol Biochem Pharmacol 99: 1-110, 1984.

6. Wang W, Jia L, Wang T, Sun W, Wu S and Wang X: Endogenous calcitonin gene-related peptide protects human alveolar epithelial cells through protein kinase Cepsilon and heat shock protein J Biol Chem 280: 20325-20330, 2005

7. MaW,Dumont Y,VercauterenF and Quirion R:Lipopolysaccharide induces calcitonin gene-related peptide in the RAW264.7 macrophage cell line. Immunology 130: 399-409, 2010.

8. McLatchie LM, Fraser NJ, Main MJ, et al: RAMPs regulate the transport and ligand specificity of the calcitonin-receptor-like receptor. Nature 393: 333-339, 1998.

9. Buckley TL, Brain SD, Rampart $M$ and Williams TJ: Time-dependent synergistic interactions between the vasodilator neuropeptide, calcitonin gene-related peptide (CGRP) and mediators of inflammation. Br J Pharmacol 103: 1515-1519, 1991

10. Fox FE, Kubin M, Cassin M, et al: Calcitonin gene-related peptide inhibits proliferation and antigen presentation by human peripheral blood mononuclear cells: effects on B7, interleukin 10 , and interleukin 12. J Invest Dermatol 108: 43-48, 1997.

11. Harzenetter MD, Novotny AR, Gais P, Molina CA, Altmayr F and Holzmann B: Negative regulation of TLR responses by the neuropeptide CGRP is mediated by the transcriptional repressor ICER. J Immunol 179: 607-615, 2007.

12. Ding W, Wagner JA and Granstein RD: CGRP, PACAP, and VIP modulate Langerhans cell function by inhibiting NF-kappaB activation. J Invest Dermatol 127: 2357-2367, 2007.

13. Rochlitzer S, Veres TZ, Kühne K, et al: The neuropeptide calcitonin gene-related peptide affects allergic airway inflammation by modulating dendritic cell function. Clin Exp Allergy 41: 1609-1621, 2011.

14. Dang H, Yang L, Wang S, Fang F and Xu F: Calcitonin gene-related peptide ameliorates hyperoxia-induced lung injury in neonatal rats. Tohoku J Exp Med 227: 129-138, 2012.

15. Ji P, Jiang T, Wang M, Wang R, Zhang L and Li Y: Denervation of capsaicin-sensitive $\mathrm{C}$ fibers increases pulmonary inflammation induced by ischemia-reperfusion in rabbits. J Surg Res 184 782-789, 2013.

16. Hartopo AB, Emoto N, Vignon-Zellweger $\mathrm{N}$, et al: Endothelin-converting enzyme-1 gene ablation attenuates pulmonary fibrosis via CGRP-cAMP/EPAC1 pathway. Am J Respir Cell Mol Biol 48: 465-476, 2013.

17. Gomes RN, Castro-Faria-Neto HC, Bozza PT, et al: Calcitonin gene-related peptide inhibits local acute inflammation and protects mice against lethal endotoxemia. Shock 24: 590-594, 2005

18. Kroeger I, Erhardt A, Abt D, et al: The neuropeptide calcitonin gene-related peptide (CGRP) prevents inflammatory liver injury in mice. J Hepatol 51: 342-353, 2009.

19. Chen H, Bai C and Wang X: The value of the lipopolysaccharide-induced acute lung injury model in respiratory medicine. Expert Rev Respir Med 4: 773-783, 2010.

20. Moitra J, Sammani S and Garcia JG: Re-evaluation of Evans Blue dye as a marker of albumin clearance in murine models of acute lung injury. Transl Res 150: 253-265, 2007.

21. Livak KJ and Schmittgen TD: Analysis of relative gene expression data using real-time quantitative PCR and the 2(-Delta Delta C(T)) method. Methods 25: 402-408, 2001.

22. Cueille C, Pidoux E, de Vernejoul MC, Ventura-Clapier R and Garel JM: Increased myocardial expression of RAMP1 and RAMP3 in rats with chronic heart failure. Biochem Biophys Res Commun 294: 340-346, 2002.

23. Yuan Y, Wang X, Zeng Q, Wu HM, Qi YF and Tang CS: Effects of continuous intermedin infusion on blood pressure and hemodynamic function in spontaneously hypertensive rats. J Geriatr Cardiol 9: 17-27, 2012.

24. Okajima K, Isobe H, Uchiba M and Harada N: Role of sensory neuron in reduction of endotoxin-induced hypotension in rats Crit Care Med 33: 847-854, 2005.
25. Sirén AL and Feuerstein G: Cardiovascular effects of rat calcitonin gene-related peptide in the conscious rat. J Pharmacol Exp Ther 247: 69-78, 1988

26. Matute-Bello G, Downey G, Moore BB, et al; Acute Lung Injury in Animals Study Group: An official American Thoracic Society workshop report: features and measurements of experimental acute lung injury in animals. Am J Respir Cell Mol Biol 44: 725-738, 2011 .

27. Peng X, Hassoun PM, Sammani S, et al: Protective effects of sphingosine 1-phosphate in murine endotoxin-induced inflammatory lung injury. Am J Respir Crit Care Med 169: 1245-1251, 2004.

28. Hippenstiel S, Witzenrath M, Schmeck B, et al: Adrenomedullin reduces endothelial hyperpermeability. Circ Res 91: 618-625, 2002

29. Aslam M, Pfeil U, Gündüz D, et al: Intermedin (adrenomedullin2) stabilizes the endothelial barrier and antagonizes thrombin-induced barrier failure in endothelial cell monolayers. Br J Pharmacol 165: 208-222, 2012.

30. Ogoshi M, Inoue K, Naruse K and Takei Y: Evolutionary history of the calcitonin gene-related peptide family in vertebrates revealed by comparative genomic analyses. Peptides 27 : 3154-3164, 2006

31. Kuwano K and Hara N: Signal transduction pathways of apoptosis and inflammation induced by the tumor necrosis factor receptor family. Am J Respir Cell Mol Biol 22: 147-149, 2000.

32. Ganter MT, Roux J, Miyazawa B, et al: Interleukin-1beta causes acute lung injury via alphavbeta5 and alphavbeta6 integrin-dependent mechanisms. Circ Res 102: 804-812, 2008.

33. Yamasawa H, Ishii Y and Kitamura S: Cytokine-induced neutrophil chemoattractant in a rat model of lipopolysaccharide-induced acute lung injury. Inflammation 23: 263-274, 1999.

34. Wolpe SD, Sherry B, Juers D, Davatelis G, Yurt RW and Cerami A: Identification and characterization of macrophage inflammatory protein 2. Proc Natl Acad Sci USA 86: 612-616, 1989.

35. Doerschuk CM, Quinlan WM, Doyle NA, et al: The role of P-selectin and ICAM-1 in acute lung injury as determined using blocking antibodies and mutant mice. J Immunol 157 4609-4614, 1996.

36. Huang J, Stohl LL, Zhou X, Ding W and Granstein RD: Calcitonin gene-related peptide inhibits chemokine production by human dermal microvascular endothelial cells. Brain Behav Immun 25: 787-799, 2011

37. Hagner S, Stahl U, Knoblauch B, McGregor GP and Lang RE: Calcitonin receptor-like receptor: identification and distribution in human peripheral tissues. Cell Tissue Res 310: 41-50, 2002.

38. Walker CS, Conner AC, Poyner DR and Hay DL: Regulation of signal transduction by calcitonin gene-related peptide receptors. Trends Pharmacol Sci 31: 476-483, 2010.

39. Mayr B and Montminy M: Transcriptional regulation by the phosphorylation-dependent factor CREB. Nat Rev Mol Cell Biol 2: 599-609, 2001

40. Altmayr F, Jusek G and Holzmann B: The neuropeptide calcitonin gene-related peptide causes repression of tumor necrosis factor-alpha transcription and suppression of ATF-2 promoter recruitment in Toll-like receptor-stimulated dendritic cells. J Biol Chem 285: 3525-3531, 2010

41. Aoki-Nagase T, Nagase T, Oh-Hashi Y, et al: Calcitonin gene-related peptide mediates acid-induced lung injury in mice. Respirology 12: 807-813, 2007.

42. Ho CY, Gu Q, Lin YS and Lee LY: Sensitivity of vagal afferent endings to chemical irritants in the rat lung. Respir Physiol 127: 113-124, 2001.

43. Kennedy TP, Johnson KJ, Kunkel RG, Ward PA, Knight PR and Finch JS: Acute acid aspiration lung injury in the rat: biphasic pathogenesis. Anesth Analg 69: 87-92, 1989.

44. Reiss LK, Uhlig U and Uhlig S: Models and mechanisms of acute lung injury caused by direct insults. Eur J Cell Biol 91: 590-601, 2012.

45. Dakhama A,Larsen GL and Gelfand EW: Calcitonin gene-related peptide: role in airway homeostasis. Curr Opin Pharmacol 4 215-220, 2004 